\title{
Art Teaching and Creative Technologies: Interactive Graphic Novels Foster Thinking and Artistic Creation
}

\author{
Agnes Papadopoulou \\ Department of Audio \& Visual Arts, \\ Ionian University, Greece
}

\begin{abstract}
At the beginning of the 21st century graphic novels faced a challenge. The appearance of comic strips on the internet creates more freedom. New features are provided to the creator and the reader. The remarkable form of graphic novels with the required choice of images and words is familiar to students of all levels due to their engagement with new technologies. Interactive graphic novels expand the boundaries of the novel with the particularity of using the audiovisual and verbal modes of expression. Interactive graphic novels immerse users into the storylines in an exciting way and allow them to become active participants in the content. They are not printed on good quality paper; interactive graphic novels are not books (not at least in the traditional, physical sense), but they maintain the same way of production and methodology. They are a hybrid type, with panels, visualisation and sound that resemble digital comics, videogames, but there is the "fell/sense" of reading. They have developed a complex vocabulary, visual, acoustic and verbal which has a significant influence on the understanding of the story. Larger narratives achieve the complexity and density of story. It is not just a "scrolling" process, that is it does not restrict the reader to a dull / restrictive navigation. It is especially important that they offer the user the freedom to navigate. The interactive collaboration of image, sound and word is a novel combination of elements in a web browser, offering a wealth of information, freedom of choice and practice of creativity. The subject matter is varied and the illustration does not depict the plot, but it is an integral part of the medium, as does the audio investment. Enrichment acts as a challenge that does not lead the reader to a surface reading.
\end{abstract}

Keywords: interactive graphic novels, visualization, creative thinking, artistic creation. 


\section{Introduction}

Graphic narration (Eisner, 2008) is a distinct and self-explanatory narrative form with excellent possibilities. The emergence of the first graphic novel is attributed to Will Eisner (1978) (A contract with God and other tenement stories) and was published in 1978 (Schumacher, 2010). A well-known comic creator, who discovered the great potential of the graphic novel, is a child of the art of succession (Eisner, 1985). It took plenty of time for it to become accepted as a form of expression. There was a tendency to move away from the comics of the kiosk and adopt features, external and internal, of books. They are examples of real aesthetic and exceptional literary quality. It is a contemporary literary genre, a multimodal genre that evolves continuously, overcoming the form of the book in interactive storytelling and using virtual reality.

Since the beginning of the genre, it has strengthened pupils' involvement in the reading process, since the creation of wider reading structures and the exemption of graphic novels from the distinctions between high and popular literature (Eco, 1994) favors pupils' varied responses. Genres are mixed and skills and knowledge of the morphological and semantic function are cultivated. There are plenty of graphic novels with a rich repertoire of various writing topics. The differentiation of graphic novels is age-depended. The subject matter and organization of the material is based on an "internal" differentiation based on the linguistic prerequisites of readers, the ability to decode the structure and the internal logic of each image, particularly in rich illustrations. In a multi-page graphic novel, it is possible to deal with complex issues and raise a critique. It often acquires an adult-oriented audience with political issues, historical issues, such as the interactive graphic novel 'Tell me your secrets' that re-tells the true story of Sir-Henry Tizard's top-secret mission to the United States. By giving away some secrets, it changed the course of WW2, but also the rest of the twentieth century (see http://www.bbc.co.uk/guides/z3b77hv). Their distinctive features are their literary element and the use of intense realism (see the use of graphic novels and interactive web comics in the Immigration Museum, Melbourne) which (use) can also lead to allegory.

Although the graphic novels originally developed on the boundaries of the printed page (Tychinski, 2012), reading them today is through personal computer screens, smartphones and tablets. As digital storytelling is gaining ground and digital display is becoming a popular way of presenting, this change becomes an occasion on reflection on technologies of representation, ways and techniques in the new media environment. In 2012, the New York Times featured an interactive article entitled Snow Fall and the Washington Post (2015) launched a sophisticated, interactive documentary entitled After the Storm. Bryan James (March 30, 2015) created an interactive show of 30 unique animals in the world that are in verge of extinction (see https://www.awwwards.com/sites/inpieces). The stake in interactive graphic novels is the way in which depiction techniques intertwine with a number of concepts, that are taught in Art Education classes, such as nature, nature and art, sex, sexism, racism, art and pop culture, national identity, identity and diversity, the concept of community, borders and migration, but also the definition of the limits of the human, the 
concept of public and private, the notion of freedom, power, systemic and productive violence.

A new framework, art and technology, is being created where new media are involved in the field of literature. There is the prospect of interaction of the verbal, audio and pictorial code so the students' reading willingness is enhanced. Graphic novels are based both on image and text, and have been influenced by modernist and postmodernist theories (Stein \& Thon, 2013). In interactive graphic novels, the aim is to make the navigation clear, not confused, so that it does not require much attention and time, depriving users of the enjoyment of the experience.

The use of the image and word combination as special qualities contributes to the development of individual skills on the part of students and the ability to choose and intervene in the story through navigation enhances the cognitive autonomy of the pupils and their cooperation with each other and with the teacher. The user selects how the story is evolving, even if one chooses the traditional version of a well-known myth or a linear evolution of history. The user will probably navigate more effectively to a well-known story than to an unknown story. The story, which is known but with changing perspectives, gives space for studying the characters more closely, evaluating interventions of visual interest and analyses of ways and consequences. The goal of interactive graphic novels is to provide more information about the characters, more content for additional events, which coincide and co-reform developments. This helps students expand the story or further develop the characters. They understand the context, the anxieties, the heroes' needs more fully than the traditional story of a fairy tale or fiction. It is a particularly creative process because it does not reproduce the story, nor does it copy it, but it can create sub-stories or a completely new story.

The choice of actions is completely in line with technological liquidity, the fluidity of reality and technological revolution (Bauman, 2010). Interactive graphic novels have several layers, characters and panels, and navigation is sometimes aided by the use of special colors and various labels. Through analyzes, discussions, and field studies that are combined (Shirky, 2011) an indepth approach to issues is provided and more opportunities are given to students to discover the world. They contribute to an understanding the world and, above all, to being able to "compete" with it. More emphasis is placed not only on the outcome but on the learning process. They act as a challenge and a source of enrichment, highlight the expressive potential and help strengthen learners as critical and creative mediators, serving the primary value which is a critical attitude towards values, messages wherever they come from.

\section{Social - communicative function}

The communication function (informative, expressive or motivational) of interactive graphic novels justifies the great interest. The student through the new technologies (Augmented Reality, Virtual Reality, Mixed Reality) is initiated into an inventive way of perceiving reality. This also advocates the decoding of the world surrounding students. However, it is an undisputed fact that the 
degraded study of images deprives the student of satisfactory skills. The goal is for the student to learn visual and semantic codes, to decode the information one receives instantly, to react with precision, but also to have the flexibility, taking into account changes in factors and changes of variables, to become a reader of images and texts as adequate one as possible and with critical consciousness. The hybrid structure of graphic novels is in line with the socio-cultural context in which interactive graphic novels are studied. Many scholars focus a lot of on form-level experiments and innovations in the genre. The form is a choice of the creator, but formulates a new generation of readers and creators (Roth, 2010). Graphic novels (printed as books) are considered as hybrid style, because they are not pure novels (Martin, 2011). The usage of the term "novel" is problematic, particularly in the case of autobiographies, historical themes (e.g., Persepolis, Palestine). Scholars suggest the term graphic narrative rather than the term graphic novel (Chute \& DeKoven, 2006, Petersen, 2010). But the term graphic novel, though not accurate, has prevailed. Efforts to use alternative terms are justified as a link to something more serious, such as literature.

The presentation of personal experiences - what Hatfield refers to as selfreferential (Hatfield, 2005) - the resourceful aspect of autobiographical and historical presentation is an important element of differentiation in graphic novels and interactive graphic novels. Marjane Satrapi's Persepolis graphic novel is an autobiographical memory of contemporary historical events. The theme of this particular graphic novel is addressed to adolescents and adults. The unique combination of word and image in the particular graphic novel cannot allow the reading to be diverted to a superficial approach without any correlation with empirical and historical circumstances. No specific system of values is forced and opportunities for expression, judgment and creativity are provided. It succeeds in demonstrating that it is possible to understand things from different aspects. Discussions begin from the perspective and experiences of Marjane Satrapi approaches to issues such as public and private opposition, the anxiety for freedom, peace and democracy (Satrapi, 2003, 2007). Whatever dominates tries to transform the image into a way of monitoring, recording and measuring. The analysis of the image means the students acquire principles of aesthetics, but mainly aims at analyzing the invisible possibilities of the image, the themes that are presented and are not apparent at first glance, especially in an interactive graphic novel, requiring an active participation from the students, this process is transformed into social experience. helps make personal discoveries, raise penetrating questions, present relations between seemingly irrelevant ideas, make suggestions for reactions and students considering the consequences. Therefore, the dominance of impulses and emotions is limited and a logical environment is not degraded and one is not distanced from interiority. Students judge and can be judged due to choices and developments in history, such as Troubadour, an interactive graphic novel covered with experimental music which exposes agonizing situations of the life of a girl growing up in a digital age. It is interesting to reflect themselves on the digital age and the system that conveys ideas and values, especially having the particular feature of being the first to grow in a digital age (Tapscott, 2009). 
The heroes in interactive (or not) graphic novels move from the field of protection in the field of risk, and the concept of risk is constantly exacerbated (such as the heroine in the interactive graphic novel The Boat, 2015). Analogue and associated thinking (Runco, Johson, Bear, 2002) -with the creation of an assessment center using possible proportions and deductions - function in a formative way for the identity of the pupils and at the same time any tendency to identify or opt-out is undermined. The interest of the students focuses on questions and aspects, perspectives on issues, developing complex interactive relationships in space, time and social context.

The interactive graphic design form is ideal for stories of heroes with high goals (a successful example is Inanimate Alice). Also, an extremely original teaching is achieved due to the form of navigation from a selectable element to another selectable element. Attempts to formulate high-level ideas are fruitful when frontiers between cognitive fields collapse and concepts of aesthetics are of the utmost importance. Findings become implicit and referential, with missing verbal details, but another kind of assessment is achieved, of features, actions, results, where needs, truths, thoughts, feelings and, most importantly, the need to restore truth and justice merge.

Roland Barthes (1985) supported the interaction of literature, namely written text with advertising, cinema, journalism. John Berger (1972) argued that the image is particularly important because it determines our position in the world by being a conscious, unique choice. He mainly analyzed paintings. Every image, every photo is one aspect or version of reality. Today, the actual tools used by the artist have been transferred to the digital world. Therefore, the verbal and non-verbal code interact in an increasingly complex way. This combination creates a synthetic framework, an amalgam of linguistic and cultural tools, exactly as in the graphic novels printed. Multimodal mechanisms of copying and pasting materials, socio-cultural parameters and semiotics are integrated, a combination of traditional media and new ways of writing and reading is created.

It is not necessary to have a single narrative, to use the texts through coherence, but to identify the formal sequence, the consistency, i.e. the ways of correlating the components of the story with the recipient / user, who is not the passive reader of the story, but contributes and holds an active role. The energetic mood of the recipient of the story emerges, connects the known with the original, the unexpected, understands the relation of the character / characters with the whole situational environment. The correlations of space, time, mode, culture through the interactive storytelling confirm that change in the means of production creates a change in the mode of assimilation. Changing shapes, colors, sizes, scales, backgrounds, optical angles, relationships of relevance and results bring knowledge to students, but at the same time they explore what the students know. This is an important factor influencing learning process (Pellegrino, 2000).

\section{Basic components of interactive graphic novels}

The interactive graphic novel is reading, with narrative development and extent and has the internal form / language of comics. There is the necessary length of a 
literature work, necessary for the narrative as well as for the complex composition. Many narratives are Chinese-box stories, that is, the writers narrate various versions. Many times we have continually alternating times, places, formulating theories and the objections / conflicts they cause, sometimes referring to real events based on scientific facts. A continuously evolving field is formed, dynamic as to relationships and roles. Meanings are co-created and transformed, observations, comparisons and links on images are made. Students distinguish expressive forms and explore the social and cultural landscape. There is a possibility to focus on design issues, technical procedures and organization of visual material (Arnheim, 2005).

Interactive graphic novels are popular and beloved to students because of narratives of anthropomorphic animals, adventure, mystery, science fiction, the existence of fairy-tale functions, mythological elements, as well as taking into consideration the subjectivity of the user and they collaborate in the interactions. Images make up a multifaceted text, as they suggest new readings. They extend the text without repeating it and work creatively. They encourage students to participate actively, inspire the intellectual representation of worlds, promote learning through study and the characteristics of complex and complex narrative. Different versions of the story form different reading perspectives. Graphic narrative (interactive or not) aims at creating broader reading structures. There is a rich store of intelligent verbal and non-verbal formats. It is more common for the creators to narrate the story with a lot of pictures and in a laconic written manner.

Will Eisner considers that the graphic novel is a means of creative expression and at the same time has the literary form with the required choice of pictures and words (Eisner, 2008). Visual representations use visual elements. The spatial relationships observed between them may be visual-spatial, metaphorically optic-spatial, resulting in the application of the force of spatial deduction in cognitive areas. Therefore, space is used as an information organizer and an aide of memory and conclusion (Tversky 1995, 2001). In the interactive graphic novel, sound has a leading role. The blending of semiotic modes presents the emitted messages with differentiated semantic loading.

The dynamics of the interactive plotting novel broadens the boundaries of multimodal literature, even how Internet and literature are involved and influence the users' reading behaviour. In the digital age, students are constantly in contact with multimodal learning and information sources (Kres \& Van Leeuwen, 2001). The multimodal text is governed by common principles as to its individual elements and is characterized by coordination of ways to same purpose. Kress attempts to define multimodality "in the broader context of the logic of speech analysis and of addressing the language as a socio-cultural phenomenon" (Kress, 2003). The graphic novel, with its particular form, is a tool for young readers who receive multiple forms of information and contributes to their familiarization with decoding mechanisms not only of the obvious meaning in each situation but also of its connotational implications. This encourages innovations, such as the creation of learning communities and the utilisation of collaborative learning environments for new technologies. 
Since the end of the 20th century, the attempt (Berger, 1972) to sharpen more effectively the critical ability of the students leads to proposing new ways of representing facts, situations and to investigate the "way of seeing" of the creator. It is interesting to exercise the practice of reading and writing and to explore the cognitive surplus of the students involved, as well as how this surplus is enriched. The possibility of recall, especially in younger children and due to the potential of technology (Jones, 1999) lends another dynamic to their engagement with literary, historical and cultural texts. Sometimes it works like a kind of idiosyncratic translation. Words and images are inextricably combined to convey meaning (Mitchell, 2003) that no one can communicate autonomously without the interdependence on the other and creating soundscapes too. The words and images are iconographically combined, like editing or collage with the familiar logos or words becoming images, the sounds of the environment, as the role of music is decisive, because it assists in a different way, possibly totally abstract. Images are converted into language and treated as complex personalities that occupy positions and identities and do not merely aid the text. For example, the text may say, "It is better to be silent!" and the picture depicts a bird that does sing, but no chirping is heard, while the sound of a clock is heart, creating other connections and escape for the hero. Words, images, sounds work together, coexist, or simply accumulate, giving different information. The visual and the verbal text may be contradictory, or harmonious, but the music may impart another intensity. There are words, images, sounds that can follow completely different paths of correlation to the story.

Words create an epistemological uncertainty, according to Algee-Hewitt (Stanford Literary Lab's Project "The Machinery of Suspence", 2015). Threatening words seem to be able to create a virtual space in which the reader can experience uncertainty. The subject of anxiety has to be characterized by the presence of words and not by how things look or how they really are. It is an exciting way not to use concepts such as anxiety or attachment in the name of objectivity, but rather to be considered as an object of study that can be tracked and quantified. There is no ontological certainty in the text (Piper, 2013), as long as anyone can choose to continue the story in another way.

Students focus on anything that is interesting for them (Gee, 2010). They are usually points that cause them thoughts or feelings about the heroes' trapping points and the departure from the present. They focus more on the opaque or dark spots, the focal points that cause agony, fear and panic. They choose more on the confrontation of the heroes with their opponents, opt for struggles, focus on descriptions of possible crimes, and comment on how and why the characters will continue. They observe the relationship of image and possible verbal description, i.e., whether it is a collaborative relationship, how they are influenced by the written text or they bypass it and insist in other elements / keys of the story. The panel is a vehicle for expressing different views by the students, particularly by expressing views on the notion of fear, danger, anxiety, creaction. They are expanding because of their choice and on related issues such as limits, the concept of exaggeration, the despotic, the untried, adopting an interpretative, but also critical approach. Questions are raised about how they will affect the hero's identity by pushing them in specific actions. They are 
involved in cognitive processes by interfering with the evolution of story, in how and why the characters move in a climate of mistrust, imposition, how to account for untold fears and especially which are the manners to respond, refuse to accept supposed truths, against deprivation, forgetfulness processes, painful remembrance, but also the creation of new paths, the control of theories and questions concerning the formulations of rules of general application.

The critical thinking of the students is cultivated, since they are involved in symbols or signifiers and adopt a form of meditation. The goal is to gain a dynamic attitude and alertness. There are no required rules or predefined shapes. One explores ways of expressing thoughts, meanings, articulating arguments, note actions. The paratext - placing special emphasis on the details of the nearby space, the existence of citizens, buildings, the creation of an atmosphere - imparts the ideological mark of the time or how through specific forms, relations are projected and the intentions of the creator are presented. According to Genette's theory $(1980,1997)$, the paratext contains everything that is "around the text", that is, the title, the subtitle, the preface, the epilogue, the back cover, the notes, the type of the paper or the cover. Therefore all the elements, the choice of letters, the composition of titles, the colours, the viewing angles, and many more are observed in the interactive graphic novel. They are observable elements, because they co-operate in the interactions and play a part in the interpretation.

\section{Pedagogical function and establishment of learning areas}

The themes of interactive graphic novels whose readership are students are based on in the past (mythology, historical events), as well as contemporary themes drawn from events of daily experience: immigration issues coexistence of peoples, cultural heritage, acquaintance with the place and its peculiarities and a great variety of others. Address to students justifies the coexistence of several occasions of the cognitive and didactic element, but primarily their desire to learn is satisfied by provoking their interest and having fun. They are involved in stories / myths that do not basically clash with logic, but they are the body of an open process, involving the student to propose interpretations, reconstruct the scenario, and even launch an irrational process of construction and deconstruction. The aim is the multiperspective viewing of the material, the construction and provision of meaning to knowledge through the intermediation of tools and signs. They acquire skills, such as reacting quickly, retaining information that is useful to them in the evolution of the story, exercising memory, observation, paying attention to specific stimuli or even creating their own content.

It is interesting that they practice and not react impulsively, that they focus on targeted movements, with accuracy and coordination. These involve presentation of consequences and phenomena. They combine events, their attention is focused on actions, they propose executive actions, while they have grouped features, reactions, and understand what it means to react instinctively and what we mean by consensus under terms, participation, or following a specific strategy. Space is given for the study of image-word relationships and sound experiments. Experimentation in the image-word relationship, as many times the interaction 
between word and image is of great interest, as well as just the one between image and sound or sound and word, it is a complex process. The important thing is that any meaning is not received and implemented only in words or images but also somewhere in between (Versaci, 2007) and additionally under the effect of music. Of particular importance is the plot, the various thematics, main and secondary, clear and implied (Metcalf, 2012).

The expansion mechanism of interpretative channels is activated, and the belief in the existence of a talented performer fades. Students comment on the intertexuality and perception ease of the material, the mechanisms of validation, cancellation or conversion of situations, the pulse of an era, how it is embodied in a particular mythical skeleton or creates foundations. The ingenuity of dialogues with mythical or literary pretexts, forgery, false and untrue representation of reality, constitute a serious play and, at the same time, a playful gravity, where analogical shapes of approaches are created, through the mythical core, issues, social practices and beliefs. Higher cognitive functions are mobilized, not just memory, attention, verbal skills, but also the ability to shift, inhibition, metacognitive functions, and use of metacognitive strategies.

Interactive graphic novels motivate even the most reluctant. They have many elements from the comics and already Alongi (1974) certifies the "magnetic attraction of children" to comics. Versaci (2001) thinks they can put a "human face" on a consistent subject, a familiar, emotional connection between students and characters of a story. Interactive digital narrative aims at attracting students' interest as an alternative way of teaching. Interactive graphic novels offer joy, creating the conditions for the possibility of creative collaboration between students but students and educators too. There is an emotional connection between the student and the lesson, which now acquires a more intimate form, as the student feels it as "their own".

Finding solutions is not easy and requires the combined use of image, text (Kittler, 2010), and music, forcing students not only to remember specific information, but to remember whole events and practice the linking of information. This helps solve problems, revealing deeper meanings and offering the possibility of self-reflection. It implies a critical way of thinking that illuminates information and sources, which are trustworthy, which are misleading, why this music soundtrack is being made and what else would they suggest. The experiential and subconscious way, where the experiences of the students are shaped by the experiences of each hero / character as well, strengthens the whole learning process. New knowledge is not compartmentalized and there is no limitation to organized education in art education issues within the school, which is in line with the tendency towards teaching based on the theory of multiple intelligence (Gardner, 1983). Indeed, by practicing them in a way that is particularly familiar, they are their own means of expression, students also practice in how they will "mover around" in a digital world, what information should be used and what will be rejected and what are the means and techniques of projection and consolidation (Glas, 2012).

The stimulation of imagination, self-motivation, experiential learning, the knowledge of the artistic alphabet, visual communication, the promotion of 
knowledge, but also the emotional stimulation, the expression of thought, the possibility to use the new media in the school of tomorrow (Vasilikopoulou, et al., 2011) does not trap students in anachronistic stereotypes, but with contemporary to them semantic stimuli, cultivates their perceptual and critical ability by transforming their interpretative horizons. Students use online information in their activity and the aim is to focus not on quantity but on quality.

In the interactive graphic novel, the power of visual allegories and their undermining is studied. There is a stylistic protocol that determines the function (Walsh, 2003), the "animation" of heroes, the creation of plot and aesthetic evaluation. It is interesting to see how the communication of additional information takes place, if there is a combination of heterogeneous objects and forms, if the space organization is diligent, how is "movement" attributed, how we are lead from the shape to the meaning and how colour tones, sizes and dimensions are manipulated. Also, the usage of shapes and which ones are chosen and why, such as the square or the rectangle, or whether there are friendly curves. Interactive graphic novels study the presentation of stories focusing on whether there is deliberate or unconscious opposition to the absolute of the often barbarous verticality, either through the panels for the evolution of history or the presentation / implicit hierarchy through the verticality, the display of obviously opposing features of the heroes. Even the number of panels for each character is of interest, and of course, if dualist concepts are made about the outcome of story, which degrades it or, on the contrary, it is driven in an original way in the synthesis of elements and information, particularly in how a teaching is presented of bending, failure, defeat.

For an interactive graphic novel aimed at young children, it is essential that the image is clear, that there are explanations, vocabulary adjusted to children, that they can communicate with the story based on the facial expressions or body language of the characters. For young ages (Weber, 2010), graphic novels must fulfill some basic specifications, such as that the story / text corresponds to the children's abilities, the characters should be children or animals, not contain scenes of violence. The difficulty in perceiving meaning in relation to the image, sound and the text should change at a rate that is not stressful and particularly demanding.

The choice of an interactive graphic novel is based on students' interests and mental needs. It is interesting to mention that graphic art begins with the description of Achilles' shield by Homer with the various representations and the succession of images (Tarlantezos, 2006). Students are studying narrative frames, lines / movement and speed elements, symbols and onomatopoeia, links to previous heroes, the timelessness of issues, past and present link elements. Resembling the way of participation in interactive graphic novels, there are graphic novels in which the story does not develop by studying the cohesion of the panels; they are not a story in the strict sense of the term, but it is an almost chaotic narration, with smaller or larger panels such as In The Shadow of No Towers, released in 2004 by Art Spiegelman. There is a connection with Mauss (Pullitzer, 1992). Art Spiegelman is now himself a victim of a terrorist attack and is presented with a mouse mask. There is a connection with previous heroes and 
there are scraps from old newspapers, achieving to highlight the tragic nature of the event (linking past and present).

In every graphic novel the visual observation of the students is practised. Time is presented through the verbal and visual modality. The reader's eye scans many moments of the story, so development becomes faster realised. There are many panels and lots of instances in space (Chute, 2010). Typically in printed graphic novels there are over six and their iconographic technique looks like collage, while in interactive graphic novels there are again several panels, emerging in a more imaginative way. Discussions about focusing on points related to distance and viewing angle, and finally how one approaches the degree of composition and complexity of the narrative help practise the students' interpretative ability (Kemp, 2014). A suggested activity for the classroom is to format stories in relation to specific topics and refer to issues such as racist, sexist, immigration, environmental and others of similar nature. Also, worksheets can be inspired by the stories through the development and depiction of central ideas, creating new incidents or completely new stories. They focus on creating symbols (Karp \& Kress, 2012), appropriate shapes, attitudes, perspectives, or propose new compositions, inventing ways to make comprehensible the relationship between the mental and the sensual. There are discussions on focus on points related to distance and viewing angle finally they make use of composition and representation tools, to also draw manually and with digital tools shapes, panels and acquire spatial and mathematical thinking, as well as using media outside the pictorial component such as speech, sound, understanding that goal determination is a major factor, because you use different tools accordingly, choosing them as the most effective.

\section{Conclusion}

The interactive graphic novel occupies an increasingly enlarged area with a mixed code, with stylization and style, utopia and dystopia, noir and science fiction. It is not a compartmentalised genre, but a vehicle, a medium through which statements and views can be expressed, conveying meanings through image, sound and words on any subject matter.

The interactive graphic novel does not contribute by strengthening the learning function and cognitive processes, because it is a modern way of reading, a new technological tool, extremely attractive, considered to be an ideal tool for mobilizing students, but emphasis is placed on the pedagogical ways and methods by which interactive graphic novels engage in the cognitive process. Interactive activities are related to knowledge in various fields of knowledge, knowledge of the history of cultures, countries, characteristics of specific time periods, and the use of pictorial elements such as the way colours and patterns, are used and the use of sound. It encourages students to think, write, communicate with their classmates, remember, move autonomously, create. In an original way, in a playful mood through the bundle of "language, picture, sound" which combines different kinds, the goal is the expressive competence of the students. The possibility is added and emphasis placed on the necessity of coexistence, knowledge and co-cultivation of different audiovisual languages, 
contributing to the passage from the word-culture to the culture of image and active participation. Students do not passively watch videos or merely play games on the computer. The optical modality is used equally to the verbal and acoustic ones. Students manage their emotions and become socialized.

The goal is not for the student to adapt to living "virtual experiences" perpetuating a typology of faces and situations, a superficial approach, ignoring complexity, but to have a filtering, a search for intertextual transformations. The joining of opposites, the self-dismantling of myth, the highlighting of different mythical versions aims at the development of a dynamic and transformative power (Jenkins, 2006). The decoding of multimodal messages of high technological quality, which are products of cooperation of several scientific fields, with political, business, advertising and consumer pursuits is an objective in the field of education. Efforts must converge on discovering the mythical substrate and where it is evident (art, spectacle, advertising), but also in areas with a more covert form, such as in social, political and national ideological constructs, where they try to create new, resilient and convincing myths to gain the trust of as many recipients for their messages as possible.

The illustration of the graphic novel is not degraded into a simple word-to-image or image to phrase match but it aims to enrich the way concepts approach, examine each aspect, all varied expressions, correlations with related concepts, or progressive deductions leading to definitions, even if they are treated as necessary restrictions. The graphic narration enriched with sound has a dynamism that influences the way readers take up and receive the story (Schwebel, 2011) offering the opportunity for multiple insights (Shipka, 2011).

Changing the narrative flow from one medium to another, that is, from the presentation of characters in the graphic novel (printing surface) to the transition on the screen, in video games, online games, gives new opportunities to text content, either by creating potential openings in the story web, further developing the story, or triggering a sense of curiosity for more information influencing the way of entertainment and contributing to commercial success. Transmediation is extended through different languages and means and functions as a component of the complex recreational and informational structure. It is a particular kind of textual narration that adopts a non-linear character. This narration creates challenges in design, in managing content and character relationships. The mixing and the particular way of articulating multiple elements from different artistic fields, ensuring participation, productivity and referring to a particular structure of the text reveals the signifying system of the work and the creation of a field of production and reproduction. 


\section{References}

Alongi, C. (1974). Response to Kay Haugaard: Comic books revisited. Reading Teacher, 27, 801-803.

Arnheim, R. (2005). Art and Visual Perception. A psychology of the Creative Eye. Athens: Themelio Publications

Barthes, R. (1985). The responsibility of forms: Critical essays on music, art and representation. NY: Hill \& Wang-Farrar.

Bauman, Z. (2010). 44 letters from the liquid modern world. Cambridge, Malden:Polity Press. Berger, J. (1972). Ways of seeing. UK: Penguin.

Bryan, J. (2015). 30 species, 30 pieces. In Pieces is a CSS-based interactive exhibition. Retrieved from https://www.awwwards.com/sites/in-pieces

Chute, H. \& Dekoven, M. (2006). Graphic narrative. Modern Fiction Studies, 52(4), 767-782, Winter.

Chute, H. (2010). Graphic women: Life narrative \& contemporary comics. NY: Columbia UP.

Glas, R. (2012). Battlefiedls of Negotiation. Amsterdam University Press.

Eco, U. (1994). The Limits of Interpretation. Indiana University Press.

Eisner, W. (1985). Comics \& sequential art. NY: Poorhouse Press.

Eisner, W. (2008). Graphic storytelling and visual narrative. USA: W.W. Norton \& Company. Gardner, H. (1983). Frames of Mind: The Theory of Multiple Intelligences. NYC: Basic Books.

Gee, J.P. (2010). New Digital Media and learning as an Emerging Area and "worked examples" as one-way forward. London: The MIT Press.

Genette, G. (1980). Narrative discourse: An essay in method. NY: Cornell University Press.

Genette, G. (1997). Palimpsests. USA: University of Nebraska.

Hatfield, C. (2005). Alternative comics. USA: University Press of Mississippi.

Jenkins, H. (2006). Convergence Culture: Where Old and New Collide. NY: New York University Press.

Jones. S. (1999). Doing Internet Research: Critical Issues and Methods for Examining the Net. London: Sage Publications.

Karp, J. \& Kress, R. (2012). Graphic novels in your school library. Chicago: American Library Association.

Kemp, M. (2014). Continutiy, Change and Progress. Athens: Gavriilidis.

Kittler, F. (2010). Optical Media. Cambridge: Polity.

Kress, G. \& Van Leeuven, T. (2001). Multimodal discourse: The modes and media of contemporary communication. NY: Oxford University Press.

Kress, G. (2003). Literacy in the new media age. NY: Routledge.

Martin, E. (2011). Graphic novels or novels graphics? The Comparatists, 35, 170-181.

Metcalf, G. (2012). The DVD novel. Santa Barbara. ABC-CLIO, LLC.

Mitchel, W.J.T. (2003). Word and image. In Nelson, R. \& Shiff, R. (Eds), Critical terms for art history (pp, 51-61). Chicago: The University of Chicago Press.

Pellegrino, J.W. (2000). Knowing what Students Know. National Academies Press.

Petersen, R. (2010). Comics, manga and graphic novels: A History of graphic narratives. California: Praeger.

Piper, A. (2013). Reading's Refrain: From Bibliography to Topology. ELH 80: 373-399. Retrieved from http:// piperlab.mcgill.ca/pdfs/Piper_ReadingsRefrain.pdf

Roth, L. (2010). Contemporary american jewish comic books: Abject pasts, heroic features. In Baskind, S. \& Omer-Sherman, R. (Eds.), The jewish graphic novel: Critical approaches (pp.3-21). New Jersey: Rutgers University Press.

Runco, M. \& Johson, D.J., Bear, P. (2002). Parents' and Teachers' Implicit Theories of Children's Creativity: A Cross- Cultural Perspective. Creativity Research Journal 14(3): 427-438. doi: 10.1207/S15326934CRJ1434_12.

Satrapi, M. (2003). Persepolis: The Story of a Childhood. USA: www.pantheonbooks.com

Satrapi, M. (2007). The Complete Persepolis. USA: Pantheon.

Schumacher, M. (2010). Will Eisner: A Dreamer's Life in Comics. Bloomsbury USA. 
Schwebel, S.L. (2011). Child Sized History: Fictions of the Past in US Classrooms. Nashville: Vanderbilt University Press.

Shipka, J. (2011). Toward a Composition Made Whole. University of Pittsburgh Press.

Shirky, C. (2011). Cognitive Surplus: Creativity and Generosity in a Connected Age. London: Penguin Press.

Stein, D. \& Thon, J.N.(Eds) (2013). From Comic Strips to Graphic Novels. Contribution to the Theory and History of Graphic Narrative. Berlin and NY: de Gruyter publications, Narratologia Series, Book 37.

Tapscott, D. (2009). Grown up digital: How the Net Generation Changing Your Work. New York: McGraw-Hill.

Tarlantezos, E. (2006). History of Comics. Athens: Aigokeros Publications.

Thomas, D., Brown, J.S. (2011). A new culture of learning. cultivating the imagination for a world of constant change. CreateSpace.

Tversky, B. (1995). Cognitive origins of conventions. In F. T. Marchese (Ed.), Understanding Images (pp. 29-53). New York: Springer-Verlag.

Tversky, B. (2001). Spatial schemas in depictions. In M. Gattis (Ed.), Spatial Schemas and Abstract Thought (pp. 79-111). Cambridge: MIT Press.

Tychinski, S. (2012). A brief history of the graphic novel. Diamond Bookshelf, May 2018. $\begin{array}{ll}\text { Received from } & \text { from }\end{array}$ http:/ / www.diamondbookshelf.com/Home/1/1/20/164?articleID=64513

Vassilikopoulou, M. \& Retalis, S. \& Nezi, M. \& Boloudakis, M. (2011). Pilot use of digital educational comics in language teaching. Educational Media International, 48 (2), 115-126 June. https:/ / doi.org/10.1080/09523987.2011.576522

Versaci, R. (2001). How comic books can change the way our students see literature: One teacher's perspective. English Journal, 91 (2), 61-67.

Versaci, R. (2007). This book contains graphic language-comics as literature. NY: Continuum.

Weber, J. (2010). The big island of children's' graphic novels. PNLA Quarterly, Pacific Northwest/Library/Association, 75 (1), 1-33. Fall.

Walsh, M. (2003). Reading pictures; What do they reveal? Young children's reading of visual texts. Reading: Literacy and Language, 37 (3), 123-130. https://doi.org/10.1046/j.0034-0472.2003.03703006.x

Wolk, D. (2007). Reading comics: How graphic novels work and what they mean. Philadelpia: Da Capo Press. 